\title{
LUCIANO ESPAÑOL
}

La influencia de las obras de Luciano de Samosata en la literatura del Siglo de Oro ha sido ampliamente descrita por los $\operatorname{crí}^{\prime}$ icos ${ }^{1}$. Pero aunque España puede vanagloriarse de haber tenido grandes helenistas a lo largo del Siglo de Oro (a juzgar por la aparición de Luciano en varios rationes studiorum lo utilizaron como libro de texto) con pocas excepciones (Vives, Laguna, los Argensola y hasta cierto punto Quevedo $)^{2}$, la mayoría de los autores quizá conoció a Luciano sólo a través de las traducciones al latín o al español ${ }^{3}$, a través de lucianistas contemporáneos como Erasmo o los autores italianos del Quattrocento cuyas obras traducidas circulaban en España en el siglo XVI ${ }^{4}$.

1 Desde Julián Apraiz, ("Apuntes para una historia de los estudios helénicos en España”, Revista de España, 1875), hasta J. K. Demetrius (Greek scholarship in Spain and Latin America, Chicago, 1965) y M. R. Lida ("La tradición clásica en España", $N R F H, 1951$ ), los críticos están de acuerdo en destacar la variedad y profundidad de la influencia de Luciano en la literatura española del Siglo de Oro. Véase tambićn MÉNÉNDEz PELAYO, "Cultura de Cervantes", Estudios y discursos de critica histórica y literaria, ed. E. Sánchez Reyes, Santander, 1942, t. 5, pp. 329-331, y Origenes de la novela, Mad rid, 1905, t. 1, p. vii.

2 Sobre Luciano y B. Leonardo de Argensola, véase OTIS G. GREEN, "Notes on the Lucianesque dialogues of Bartolomé Leonardo de Argensola", $H R, 3$ (1935). Sobre Quevedo véase SYLVIA BÉNICHOU-ROUBAUD, "Quevedo helenista (El Anacreón castellano)", NRFH, 14 (1960), pp. 51-72.

3 Para bibliografía sobre las traducciones véase THEODORE BEARDSLEY, 'Hispanoclassical translation printed between 1482 and 1699. Pittsburgh, 1970. Las críticas de Menéndez Pelayo a las traducciones de Luciano, aunque bastante generales, son acertadas en cuanto a su calidad (Biblioteca de traductores españoles, ed. E. Sáncuez Reyes, ts. 54-57 de las Obras completas, Santander, 1952-53). Sobre las dos traducciones del siglo XV del Dialogus mortuorum xii (la primera tal vez de Vasco Ramírez Guzmán, la segunda de Martín de Avila), véase A. J. DARNET, "Un diálogo de Luciano romanceado en el siglo XV", Cuadernos del Instituto de Filología de Buenos Aires, 1 (1925), 139-159; el artículo más completo de P. FERnANDo RUBIO, "Dos traducciones castellanas de un diálogo de Luciano hechas en el siglo XV", $C D, 162$ (1950), 353-370, y MENÉNDEZ Y PELAYO, Traductores españoles, t. 4, p. 126.

4 En su obra citada, pp. 118-119, T. Beardsley comenta la importancia de las traducciones "intermedias" en la literatura clásica española: "Thus, it seems to us conservative and even obvious to maintain that to a large extent the amount of Classical influence on Spanish literature in the sixteenth and seventeen th centuries will be controlled by the Classical works translated into Spanish or by other intermediaries in the realm of existing literary traditions, imitations and commentaries. In this respect the diffusion of the Classics through the intermediary of Italian literature must not be ignored". Las traducciones italianas de Luciano más consultadas fueron, al parecer, Dialoghi di Luciano filosofo (Venecia, 1527) y la de 
La frecuencia con que se han traducido las obras de Luciano al español, da fe de su constante popularidad a través de los siglos XVI y XVII: en números de traducciones Luciano ocupa el cuarto lugar después de Esopo, Aristóteles y Epícteto ${ }^{5}$. Pero esas traducciones de Luciano eran a veces bastante distintas al original en estilo e ideología. De las versiones españolas de Luciano del siglo XVI, los Diálogos ${ }^{6}$ atribuidos un poco a la ligera al heterodoxo Juan de Enzinas ${ }^{7}-$, publicados en 1550 en la famosa imprenta de Sebastian Gryphius ${ }^{8}$, es a la vez la más extensa y la más interesante para el estudio de la estilística y de la metamorfosis cultural que ocurre en las traducciones de lenguas clásicas (ya que probablemente se utilizaron textos griegos y latinos de Luciano para traducir los Diálogos al español).

En grado y calidad de desviación del modelo, los Diálogos de 1550 son paradigma de las traducciones más libres de la literatura popular del Renacimiento. La línea trazada por los fidus interpres como Guarino o Erasmo ${ }^{9}$, la integridad del texto original y la licencia del tra-

Niccolò da Lonigo, Dilettevoli dialoghi (Venecia, 1535; reimpr. en 1541, 1543, 1551). E1 latín era también de gran ayuda para la comprensión de las obras griegas: hacia 1550 casi todo el corpus Lucianeum podía leerse en latín. Algunos tex tos sólo aparecen en ediciones escolares, como la de Francisco Vergara (Alcalá, 1529). Otras ediciones, como el esfuerzo conjunto de Tomás Moro y Erasmo, eran amplias y circularon profusamente en Europa. Hasta ahora, el mejor estudio sobre el Luciano de Moro-Erasmo es el de CRAIG R. THOMPSON, The translations of Lucian by Erasmus and St. Thomas More, Ithaca, N. Y., 1940. Un estudio comparativo de los estilos latinos de Moro y Erasmo se halla en D. F. S. ThomsPoN, "The Latinity of Erasmus", en Erasmus, ed. T. A. Dorey, London, 1970, pp. $117-118$.

5 T. BEAR DSLEY, Hispano-classical translations, p. 114.

6 El título completo es Diálogos de Luciano no menos ingeniosos que provechosos traducidos de griego en lengua castellana, Lyon, 1550.

7 Ya que en los diálogos no hay nombre ni seudónimo del traductor, las atribuciones han sido numerosas. Menéndez y Pelayo opina que el traductor es Enzinas tanto de los Diálogos de Luciano como de la Historia verdadera de 1551, a base de la similitud de estilo en ambas y en las Vidas de Plutarco, cuya traducción, se sabe, es de Enzinas (Traductores españoles, t. 2, p. 28). M. Morreale encuentra la atribución "muy convincente" (cit. por T. Beardsley, pp. 141-142). Lasso de la Vega compara los Diálogos y Vidas ("Traducciones españolas de las Vidas de Plutarco", EClás, 6, 1961, p. 488) y comenta que "la tipografía recuerda la de los Diálogos de Luciano. . . cuya traducción atribuyen algunos a Enzinas, y, desde luego, el estilo peculiarísimo del burgalés y su especial técnica traductoria parecen denunciarse igualmente en esta versión". Aunque no es sorprendente que ambas obras tengan la misma tipografía y los comentarios del crítico sobre la técnica y el estilo de la traducción son seductores, no se llega a conclusiones definitivas en el artículo. Es sin duda curioso comparar la unanimidad con que se declara a Enzinas traductor con la falta de pruebas basadas en la comparación de los tres textos. Es raro inclusive que ninguno de los críticos haya aprovechado los datos biográficos que, quizá, ayudarían a justificar el interés de Enzinas en una empresa como los Diálogos: habría sido extraño que en sus clases de griego en Alcalá, Lovaina y Wittenberg no hubiesen incluido a Luciano. Enzinas pasó la mayor parte de su vida adulta rodeado de luminarias interesadas en Luciano. La influencia de Erasmo todavía era reciente en Lovaina en 1540. Melanchthon, en cuya casa Enzinas era huésped, había editado la Calumnia de Luciano. También es de importancia la correspondencia entre Enzinas y Celio Secondo Curione, el autor del lucianesco Pasquino in estasi. Finalmente, los Diálogos podrían ser producto de los años de Enzinas como profesor de griego en Cambridge (1548-1549).

8 Sobre la importancia de Lyon como centro de publicaciones de la literatura de la Reforma, véase Bibliographie lyonnaise, 8me série, ed. J. Baudrier, Paris, 1910, pp. 11-35.

9 Guarino y Erasmo buscaban la fidelidad en la traducción. Sobre el primero véase 
ductor era todavía (salvo en el caso de la Biblia o en el de las traducciones "gramaticales" o literales) ${ }^{10}$ una licencia heredada de la antigüedad" $^{11}$ : la tendencia medieval establecida por la sentencia de Rabano Mauro "ad nostrum dogma convertimus"12 de la que se hace eco Pero Mexía cuando sugiere que los autores griegos se han de traducir "cristianamente, aunque algo se torciese la letra"13. La misma ejemplaridad en la selección del texto y la libertad para manejar el contenido que caracterizan a la mayoría de las traducciones seculares son evidentes en los Diálogos en español.

Aunque el lector moderno probablemente asocie a Luciano con el escepticismo de Voltaire, para el Renacimiento las obras de Luciano eran ejemplares. Al seleccionar a Luciano, el traductor simplemente confirma el concepto generalmente aceptado en su época de que el satirista es un filósofo moral. Desde el principio de los estudios griegos en Italia, se valoró a Luciano por su ejemplaridad como estilista y moralista ${ }^{14}$. Sucesivas generaciones de traductores y editores confirman este punto de vista que pasa a España al final del siglo XV y se fortalece en el siguiente con la tendencia particularmente cristiana del humanismo en España y con la apreciación de Erasmo: "Luciano nihil fere triviale solet profícisci" ${ }^{15}$. Desde las primeras traducciones

W. H. WOODWARD, Studies in education, t. 2, p. 101. Para el segundo, la paráfrasis es una "smoke-screen thrown up by unskillful translator as the cuttle-fish throws up its cloud of darkness" (M. M. PHILliPS, Erasmus and the classics, en Erasmus, p. 8). Ambos eran, en su época, modelos de fidus interpres: cuando Franciscn Vergara sugiere un ratio studiorum en su De graecae linguae grammatica, insisten en una traducción "quae fidelis, apta et elegans sit; quales habentur Gazae. . Guarini, Budaei et Erasmi” (pp. 8-9).

10 FLORA ROSS AMOS, Early theories of translation, New York, 1920, pp. 99, 109. Las traducciones de los textos religiosos, especialmente durante la Reforma, tendían a los mismos niveles de precisión que caracterizaban a las versiones vernáculas de la Biblia (ibid., p. 118).

11 La "tendencia constante a las traducciones libres", característica del siglo XV (C. ROBINSON, Luciani dialogi, p. 364), no cambia significativamente en el siglo XVI.

12 Citado por J. J. MURPHY, Three medieval rhetorical arts, Berkeley, 1971, p. xiv. En su Institutio clericalis, Rabano Mauro argumenta: "If we wish to read the poems and books of the gentiles. . . we must take as our type the captive women in Deuteronomy... If an Israelite should want her as a wife, he should shave her head, cut off her nails and pluck her eyebrows... By the same token, we customarily do this when a book of secular learning comes into our hands. If we find anything useful in it, we absorb it into our teaching. If there is anything superfluous concerning idols, love or purely segular affairs, we reject it. We shave the head of some books, we cut the nails of other with razor-sharp scissor" (ALEX PREMINGER et al., Classical and medieval literary criticism, New York, 1974 , p. 265).

13 Silva de varia lección, Prólogo.

14 En el prefacio a la traducción de Caron de Luciano de Rinuccio Tessalo d'Arezzo (c. 1440), el autor se refiere a Luciano como philosophus y recomienda la obra a los lectores que buscan "bonos mores" e instrucción en el vivir humano (D. P. LOCKWOOD, "De Rinutio Aretino Graecarum litterarum interprete", Harvard studies in Classical Philology, t. 24, p. 53). Los moralizantes Palinurus y Dialogus veritatis et philalethis de Maffeo Vegio, los cuales forman parte del seudo-lucianismo del siguiente siglo, hacen eco a la fama de Luciano como filósofo moralista. La sátira moral y social de Intercoenales de Alberti, confirma este punto de vista sobre el satirista griego, lo mismo que otras imitaciones como el Charon de Pontano y el Somnium de Aeneas Sylvius Piccolomini.

15 El hecho de que Erasmo utilice a Luciano para la traducción y la educación es una 
españolas de Luciano en el siglo XV hasta los Diálogos morales de Herrera Maldonado (1621), la selección y el tratamiento del original revela motivaciones didácticas, excepto el caso especial de la Tragodopodagra de Laguna ${ }^{16}$. Las obras de Alfonso de Valdés, la tendencia a asociar algunos textos de Luciano con obras ciceronianas de tema similar $^{17}$, el uso de Luciano en Alcalá y en las escuelas jesuitas ${ }^{18}$ y la aparición de sus personajes en el teatro jesuita revelan que en esa época se consideraba a Luciano como un moralista satírico ${ }^{19}$. Por eso, al escoger Toxaris o de la amistad, Carón o los contemplantes, El gallo, Menipo en los abismos y Menipo sobre las nubes o Icaromenipo, el traductor compiló una antología de las obras más populares y edificantes de Luciano ${ }^{20}$

El Luciano español de 1550 representa también la literatura humanística de la época, en cuanto las elaboraciones del tex to original revelan una marcada dependencia de los schemata verborum que prescribe la retórica clásica para la composición en prosa ${ }^{21}$. Aunque el traductor se siente hasta cierto punto libre para elaborar, no elabora libremente: la mayoría de los cambios en pequeña escala correspon. den a los colores retóricos.

Por último, la edición española es interesante por la infiltración, minuciosa aunque rara vez inoportuna, del contexto cultural e ideo-

de las muchas manifestaciones de su admiración por los humanistas italianos del Quattrocento. Los prefacios de sus traducciones señalan el valor moral de los diálogos: Gallo ejemplifica el utile dulci (Dialogi, ed. C. Robinson, p. 425); Toxaris es frugifer (ibid, p. 425); Alexander tiene frugiferae nugae (ibid., p. 366). De hecho, "so certain is Erasmus of Lucian's qualities as a morahst, that in assessing the De Astrologia, he presumes that it must have a moral content: "Nam a Luciano nihil fere triviale solet proficisci! "” (ibid., p. 366).

16 Laguna se distingue como traductor de Luciano al español, porque elige las obras de entretenimiento escolástico. Describe el Tragodopodagra como "non minus erudit us quam festivus et elegans" (Aristotelis de Mundo. . Luciano Dialogus, portadilla). También es la única traducción de parodia griega en verso del Siglo de Oro.

17 Juan de Jarava traduce Icaromenipo en 1544 y en 1549 publica el Somnium Scipio nis y la Paradoxa de Cicerón. Fray Ángel Cornejo publica cl Toxaris de Luciano con el Laelius de Cicerón en su Arte de amistad con maravillosos exemplos (Medina del Campo, 1548).

18 Francisco Vergara sugiere junto con Isócrates y Esopo "Luciani breviores Dialogos aut eius genera aliquid quod festiva brevitate vel sententiae utilitate arrideat. ." (De Graecae linguae grammatica, p. 1). Sobre el lugar que ocupaba Luciano en los estudios griegos, véase GARcía SoriAno, "El teatro de colegio en España", BRAE, 14 (1927), p. 251 ; y sobre su ubicación en el curriculum jesuita, JERónImo NADAL, De Studiis societatis en Monumenta pedagogica societatis Jesu, ed. C. Gómez Rodeles, Madrid, 1901, p. 89. García Soriano publica varias obras en donde aparecen Menipo, Momo y Parásito; para el típicamente lucianesco "desfile de ánimas", véase el Christi Nuncius de Acevedo.

19 Los autores protestantes de la sátira lucianesca están mejor representados por Curione (Pasquillorum tomi duo, Pasquilli Ecstatici cum Marphorio Dialogus), Francesco Negri (Tragedia del libero arbitrio) y Bernardino Ochino.

20 C. R. THOMPSON, The translations of Lucian, p. 4.

21 Sobre la oratoria clásica como base de la composición en prosa, véase M. W. CROLL, "The anti-Ciceronian movement", en Style, rhetoric and rhythm, Princeton, 1966, p. 55. La exposición de Kcith Whinnom sobre la retórica y la composición en prosa cn Cárcel de amor es uno de los pocos cstudios que se dirige directa y perspicazmente al tema de las categorías retóricas en la creación de prosa original (Diego de San Pedro, New York, 1975, pp. 71-77, 114-116). 
lógico del traductor. Aunque los críticos que han estudiado los Diálogos están de acuerdo en que éstos son más o menos libres, no se han estudiado ni los cambios específicos y su efecto ni la sensibilidad que rige las alteraciones; tampoco se han visto los Diálogos en el contexto de la prosa de la época ni se ha evaluado la obra como creación literaria en $\mathrm{si}^{2}{ }^{22}$.

Un estudio de las diferencias entre los Diálogos y la versión original, que debe haber sido accesible a muy pocos, o la versión más popular y escrupulosamente correcta en latín como la de Erasmo, revela un Luciano cambiado en estilo, ideología y sensibilidad, quizá el único que la mayoría de los autores y lectores españoles podían haber conocido.

Los cambios más obvios hechos al tex to griego (o los que se encuentran en el texto de Erasmo) son la minuciosa amplificación de palabras, $y$ hasta de frases enteras ${ }^{23}$. En este aspecto, el traductor se acomoda a los ideales estilísticos de plenitudo y copia ${ }^{24}$, y la importancia que da a la amplificación tanto en el contenido como en las palabras, a veces a costa de la corrección ${ }^{25}$, caracteriza la etapa ciceroniana de la prosa renacentista. La elegancia de la brevitas de Luciano será descubierta por la siguiente generación de helenistas, al cobrar fuerza los movimientos anti-ciceroniano y neoestoico en los círculos litera$\operatorname{rios}^{26}$.

Además de la tendencia a la amplificación en la retórica clásica,

22 Mcnéndez Pelayo, al cscribir sobre las Vidas de Plutarco y sobre Luciano, dice: "Las traducciones de Enzinas están hechas en estilo suelto, correcto y castizo. . . Merece censura, no obstante, nuestro egregio helenista, por haber incurrido muchas veces en ampli. ficación y desleimiento, llegando hasta añadir pensamientos propios a los de Plutarco y Luciano" (Traductores españoles, t. 2, p. 28). José López Ruega coincide con Lasso de la Vega en que Enzinas "pone mucho de su cosecha en sus traducciones, lo que las transforma casi en paráfrasis" (Helenistas españoles del siglo xvl, Madrid, 1982, p. 389).

$23 \mathrm{La}$ referencia a las citas en griego corresponde al párrafo del original; los números entre paréntesis, a la cita en español que se refieren al número de folio de los Diálogos; los pasajes correspondientes en la traducción de Erasmo provienen de Opera Omnia, in trod. Christopher Robinson, Amsterdam, 1965.

24 Cicerón establece categóricamente: "Suma autem laus eloquentias est amplificare rem ornando" (De Oratore, 3, 26, 104). La amplificación proporcionaba a los humanistas abundancia de material del cual servirse. Esta tendencia enciclopedista ya se encuentra en la sugerencia de Gaurino de que los estudiantes recopilaran diccionarios rudimentarios, extractos y proverbios de sus lecturas (W. H. WoODWARD, Studies in education p. 40). Erasmo afirma el método al enfatizar "devices for adding to our intellectual stores, which, trivial as they may seem individually, have a distinct cumulative value" (De ratione studii, citado por H. W. WOODWARD, Desiderius Erasmus concerning the aim and method of education, Cambridge, 1904, p. 166).

$25 \mathrm{El}$ deseo de crear elocuencia se origina antes de la adquisición de un conocimiento sólido del griego: Coluccio Salutati ordena a Loschi que adorne la lliada con elóquentia para hacerla "más propia, más espléndida y más sonora". Véanse sus consejos a Bruni acerca de Aristóteles en Rhetoric and philosophy in Renaissance humanism, J. E. SIEGEL, Princeton, 1968, pp. 114-136.

26 Para la relación entre el aticismo y la brevedad, ver M. W. CroLL, Style, rhetoric and rhythm, p. 71. En España, Pedro Simón Abril alabará De Historia conscribenda de Luciano como "más discreta que larga" (citado por M. MorreAle, Pedro Simón Abril, Madrid, 1949, p. 48). Jáuregui verá en Luciano el antídoto para los excesos gongoristas. 
Quintiliano, Aulo Gelio y Erasmo la recomiendan específicamente en la traducción del griego al latín, observacción que podría aplicarse aún más a las traducciones españolas del griego ${ }^{27}$.

La forma más simple de amplificación que se destaca en la retórica clásica, la sinonimia ${ }^{28}$, invade el texto de los Diálogos. Así ocu-

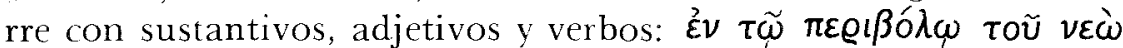
(Tox., 6) "en los claustros y portales del templo" (7a) ${ }^{29} ;$ हैं $\pi 0 \lambda \lambda \tilde{\eta}$ $\tau \tilde{\eta} \pi \varepsilon \varrho \iota \delta \delta \omega$ (Gall., 19), "alguna revolución y curso de siglos" $(92 \mathrm{a})^{30}$; $\lambda \varepsilon \pi \tau \delta \tau \varepsilon \varrho o \nu$ (Caron, 5) se interpreta "demasiadamente deli-

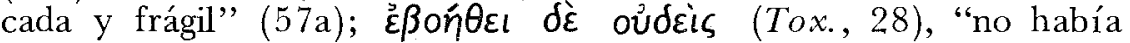
ninguno que le ayudase ni favoreciese" $(26 \mathrm{a})^{31}$.

A menudo una sola frase se convierte en dos otres, que reiteran (in-

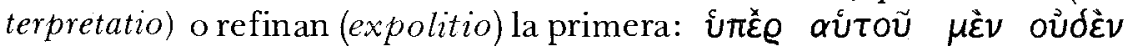

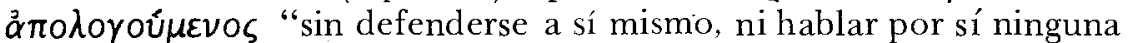
cosa",32. Toxaris, 34 (véase también Caron, 11;61 b). Hasta una palabra puede extenderse a una frase: oủ $a v o \gamma v \omega ́ \mu$ oves "muy diestros en saber la propiedad y natura de todas las cosas celestes y terrestres" $(124 \mathrm{~b})^{33}$. Icar., 5. En algunos casos la amplificación es redundante:

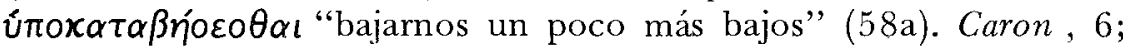

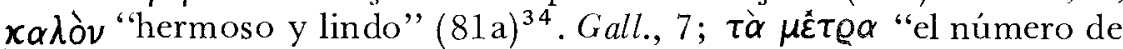

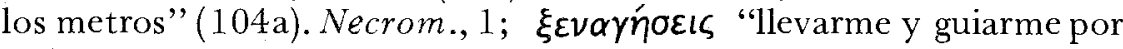
todas partes como a hombre peregrino, y que tan poco conocimiento tiene en la tierra" (52a). Caron, 1.

También hay ciertas amplificaciones necesarias en glosas marginales o en frases breves insertadas en el texto para explicar referencias eruditas tales como la Pirámide o las estatuas de Memnón, o nombres propios y referencias mitológicas ${ }^{35}$. Aparte de las amplificaciones, el

27 Véase Quintiliano De Institutione oratoria, xii, 10, 33. Aulo Gelio, Noctes Atticae, xi, 15, 1. Erasmo establece en su De Copia, el tratado más completo de la época, y como el autor declara, el primero en su tipo sobre la amplificación ("Letter to Guillaume Budé", Oct. 28, 1516): "Vertend is Graecis auctoribus non mediocriter augebimus sermonis copiam, propterea quod haec lingua rerum verborumque ditissima est".

28 Cicerón, De partitione oratoria, 53. Fronto habla de la importancia de "coleccionar sinónimos" (Correspondence, ed. C. R. Havies, Loeb, New York, 1920. Erasmo siguiendo a Quintiliano $(\mathrm{x}, 1,5)$ se refiere a los sinónimos como "opes" y dedica el capítulo 11 de $D e$ Copia a su uso.

29 Cf. Erasmo, Opera omnia, I, p. 427: "Quin et in portico templi eadem..."

30 Ibid., p. 481: ". . idque saepius longo nimirum saeculorum orbe et recursu".

31 Io id., p. 435: "Nec opitulabitur quispiam. . ."

$32 \mathrm{Ib}$ id., p. 437: ". . quum interim pro seipso nihil respondebat. . "

33 Ibid., p. 411: ". . coelestium rerum peritos. .."

34 Ibid., p. 475: "Multam auri vim vidi, Pythagora, quam putas pulchri".

35 ". . Se partió para Egipto por ver unas torres muy altas que allí había llamadas Pirámides y ciertas aves llamadas Memnonas. Porque via [sic] oído que siendo muy altas las torres no echaban sombra, y que las aves Memnonas hablaban cuando salía el sol" (23b). El traductor ha confundido las míticas aves que se decía que habían salido de la pira funeral de Memnón, rey de Etiopía, con la colosal estatua de Tebas en Egipto de la cual se decía que cantaba al amanecer. Otras aclaraciones del traductor son: "Solón filósofo ateniense" (60b); "el cerco de Troya" (89) por tà है $v$ "T $\lambda \hat{i} \omega$; "si oyeras hablar a la barquilla de aquella nao a quien Homero pone por nombre Argo..." (76); "Verás en lo alto las Parcas

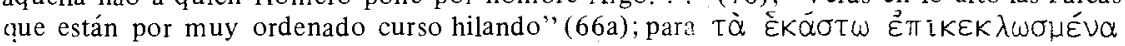


traductor a menudo añade adjetivos que caracterizan, y cláusulas que o bien describen cualidades inherentes o especifican y particularizan:

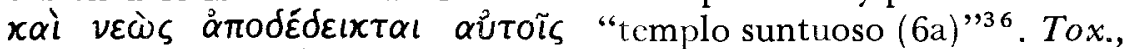

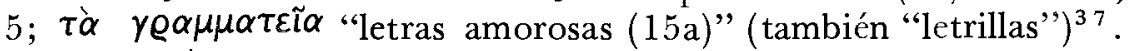

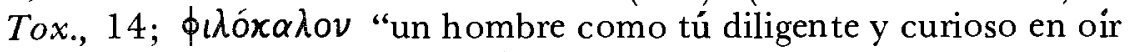
y ver cosas nuevas y señaladas (105a)". Necrom., 2.

El traductor es más exacto en lo relacionado con los lugares, y con frecuencia señala el tiempo y hasta la secuencia en donde Luciano no

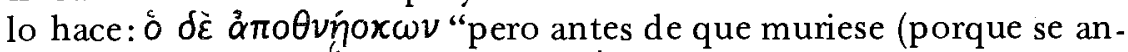

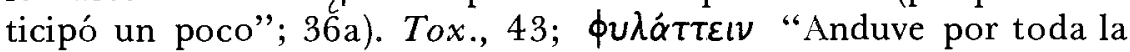
casa arriba abajo buscando de rincón en rincón(100b)"38. Gall., 30.

Amplificaciones y adiciones como éstas se encuentran a lo largo de toda la obra y hacen los Díálogos mucho menos agudos y sucintos, más relajados en el ritmo de la lectura que el original griego. Pero los personajes de la versión española se presentan de manera más visual (evidentia o illustratio) que los del original, con lo que las descripciones son más vívidas para el lector: $\tau i$ фìns $\widetilde{\omega}$ Tóg $\alpha Q \iota$ "¿Qué quie-

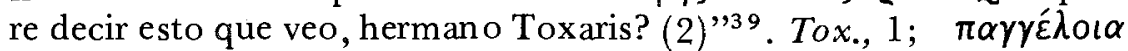
$\tau \alpha \tilde{u} \tau \alpha$ "Todas estas cosas que veo parecen demasiadamente vanas y de burla" $(67 \mathrm{a})^{40}$. Caron, 17.

Generalmente el léxico del traductor es más enfático que el de Luciano: ì $\gamma$ oú $\mu \varepsilon \theta \alpha$ (Tox., 1): "teniendo por cosa muy cierta" (3b);

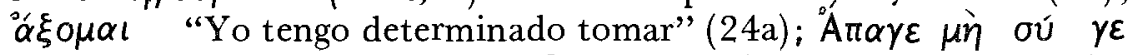
(Tox., 25), "no quiera Dios que tú hagas semejante desatino" $(24 \mathrm{a})^{41}$.

El autor también eleva el tono del tex to con requerimientos ("tenlo por oráculos divinos", 89; "te ruego que. . .", 75 ; "te hago saber que. ..", 2la; "hágote saber que. ..", 54. O exagera las cantidades

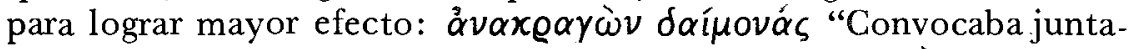

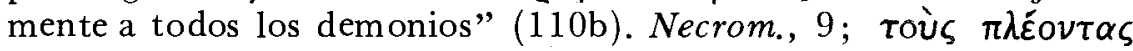
"una multitud infinita y confusa" (64b). Caron, 15. El traductor usa querer como auxiliar modal para acentuar la fuerza del verbo: $\alpha \pi \alpha \hat{\alpha} \xi \omega$

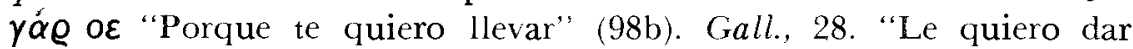
un gran puñete en la maxilla" (100b; adición del traductor a Gall., 29).

Los pronombres demostrativos indefinidos y los interrogativos indirectos se especifican para elevar el impacto emocional del texto: $x \alpha \grave{i} \tau \grave{\alpha} \tau o \iota \alpha \tilde{v} \tau \alpha$ "y otros semejantes afectos y perturbaciones del

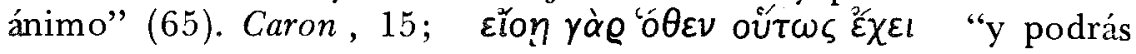

de Luciano, el traductor explica: "...todas las cosas que para cada uno de los mortales están determinadas en el huso y estambre de las Parcas, que es decreto inviolable" (64a).

36 Erasmo, p. 426: "Apud nos vero et templum ostenditur ambobus illis".

$37 \mathrm{Ibid}$., p. 431 : "litterulae".

38 Se agrega a Toxaris, 8 "Nunca pensará que en los tiempos pasados" (9a).

39 Erasmo, p. 425: "Quid ais, Toxaris?"

40 El traductor aumenta en Toxaris, 6: "Y porque no ignores lo que hicieron, te quiero contar en pocas palabras alguna parte de su historia, la cual veis en estas paredes pintadas" (7a).

41 Para más ejemplos, compárese Gallo, 9 y Diálogos, 82b; Gallo, 17 y Diálogos, 89. 
bien entender la causa porque está tan afligido y mal contento" (100b). Gall., 29.

El traductor consigue mayor énfasis substituyendo los adjetivos por sus grados comparativos y superlativos o haciendo los términos

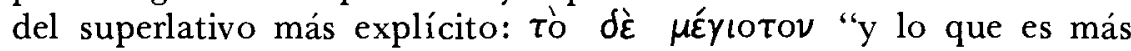
grave y más intolerable que todo el resto" (97b). Gall., 14; toגù

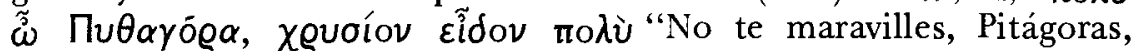
porque es grande y muy grande" (81a). Gall., $7^{42}$.

El efecto de las alteraciones mencionadas es de un profundo impacto emotivo. El siguiente ejemplo es típico tanto de la exaltación del traductor como de la restringida concisión de Luciano: ótav dé

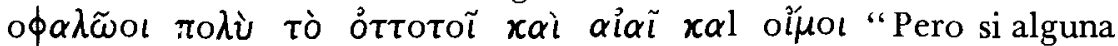
vez les viene adversa la fortuna y se hallan burlados de su esperanza, a la hora comienza a lamentarse nunca cesando su boca de repetir aquella dolorosa y triste canción, ay cuitado, ay desdichado, ay malaventurado..." (67b). Caron, 17. (Véase también 20b. Tox., 20).

La gran mayoría de las alteraciones, ya sean de res o de verba, no son amplificaciones mecánicas, ya que sirven para intensificar la fuerza emocional de los personajes más bien fríos de Luciano, y para ele. var el impacto afectivo de los Diálogos. Este repetido énfasis corresponde, antes que nada, a la dependencia general del traductor para sus ampliaciones de una retórica clásica diseñada para conmover al público: progymnasmata tal como la suasoria y la controversia que ejercitaba el estudiante renacentista al estilo del discurso forense en el cual era fundamental despertar las emociones.

En un sentido amplio, el tono emocional más elevado de los Diálogos en comparación con el original es típico de este período en cuanto refleja el valor de los sentimientos y las percepciones del individuo en el pensamiento renacentista ${ }^{43}$ : la herencia acumulada y matizada del platonismo, ciertos rasgos de misticismo medieval, el agustinianismo con su énfasis en la conciencia individual ${ }^{44}$ y su teoría de la personalidad bien desarrollada ${ }^{45}$, así como las menos estudiadas instigaciones al individualismo tales como los manuales confesionales del Quattrocento ${ }^{46}$, validan una sensibilidad más explícitamente subje-

42 Aun invenciones libres del autor tales como: "y lo que más de reír es" (67a) ilustran esta tendencia.

43 Kristeller afirma que "another characteristic feature [del pensamiento renacentista] is the tendency to express and to consider worth expressing the concrete uniqueness of one's feelings, opinions, experiences and surroundings, a tendency which appears in the biographical and descriptive literature of the time" "The humanist movement in Renaissance thought" en Renaissance thought: The classic, scholastic and humanistic strains, ed. rev. y aum. de The classics and Renaissance thought, New York, 1961, p. 20). La defensa de Poliziano de su anticiceronianismo es ejemplo de esta nueva sensibilidad: "Alguno dirá: «no expresas a Ciccrón ». Yo contesto: «No soy Cicerón. Lo que realmente expreso es a mi mismo»" (SANDYS, History of classical scholarship, t. 2, p. 85).

44 PAUL OSCAR KRISTEller, "The philosophy of man", en Renaissance thought, p. 127.

45 PAUL HENRY, Saint Augustine on personality, New York, 1960.

46 T. C. PRICE ZIMMERMANN, "Confession and autobiography in the early Renaissance" en Renaissance: Studies in honor of Hans Baron, De Kalb, 111., 1971, pp. 119-140. 
tiva. Es razonable con esta nueva conciencia que Melanch thon acuñe el término "psicología"47. La llamada novela sentimental ${ }^{48}$, la égloga pastoral, tràtados tales como De anima et vita (1538) de Vives y Castillo interior de Santa Teresa ${ }^{49}$ exploran de diferente manera y por diferentes razones las obras de la mente y resultan más fascinantes por su dilema en común al estudiar nuevos campos antes de que se hubieran desarrollado categorías y el léxico pertinente a tales disciplinas.

Las amplificaciones más descriptivas elevan las impresiones afecti-

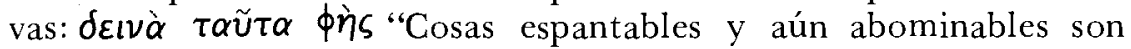

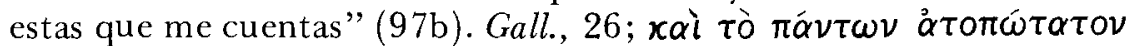
"Y lo que sobre todo yo tenía por más monstruoso y fuera de todos

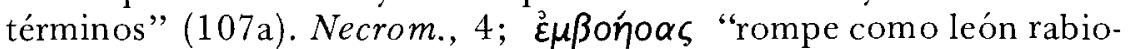
so... dando grandes voces con tanto ímpetu. .." $(45 \mathrm{a})^{50}$. Tox., 55.

En la traducción los personajes son en la acción mucho más enfáticos que los originales, y sobre todo, el traductor da al griego (que, es in teresante notar, Juan de Valdés consideró un buen ejemplo del lenguaje hablado más que del escrito ${ }^{51}$, un matiz más gráficamente oral:

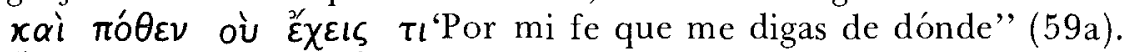

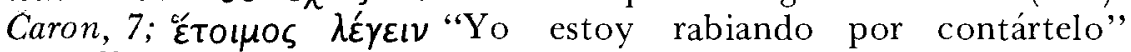
$(80 \mathrm{~b})^{52}$. Gall., 15. (Véase también Gallus, 15, 88a; Toxaris, 5a; 40b).

Asimismo, el énfasis del traductor en la exhortación revela la manera fría y apagada en la que actúan los personajes de Luciano que, en la traducción, están más conscientes de sus emociones, al mismo tiempo que hacen más explícitas las dimensionè̀ de su vida interior al usar el vocabulario de los manuales contemporáneos de oración y

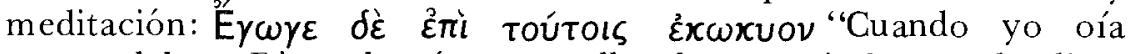
estas palabras, Dios sabe cómo yo solloçaba y sospiraba por el peligro en que veía a mi amigo" $(47 \mathrm{~b})^{53}$. Tox., 60 (Véase también Tox., 42;

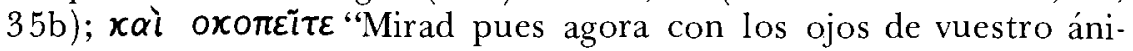

47 Aunque a veces se le adjudica la creación del término a Rudolf Goeckel (1547-1628) ("Psychological. schools in European thought", Dictionary of the history of ideas, ed. Philip P. Weiner, New York, 1973), parecería que Melanchthon se le adelantó varias décadas en la creación del término (Dictionary of psychology and related fields, ed. H. G. Beigel, New York, 1971).

48 Para una discusión sobre el género, véase Keith Whinnom, Diego de San Pedro.

49 Sobre la contribución de estas obras a la psicología descriptiva de las emociones, véase Brett's history of psychology, pp. 297-300, 323-330.

50 De la misma manera, "con fuego y crueles azotes" (17b) eleva Toxaris, 17; “¿Qué quiere decir este monstruo tan espantable?" (76a), Gallo, 2; "dando tristes alaridos y gemidos muy dolorosos" (11b) para Necromancia, 11.

51 "VALDÉS: Porque Luciano, de los autores griegos en que yo he leído, es el que más se allega al hablar ordinario, os daré dél los exemplos MARCIO: Más los quisiera de Demóstenes. VALDÉs: Y aun yo holgara de dároslos siquiera de Isócrates, pero contentaos con que os dé de lo que tengo" (Diálogo de la lengua, ed. J. M. Lope Blanch. Madrid, 1969, p. 56). Valdés continúa comparando giros de la lengua comunes y populares con sus análogos en Luciano.

52 Erasmo, p. 475: "Gestio narrare..."

53 Cf. Toxaris, 21 y Diálogos, 21 a: “¿Perecieron los hombres, Mnesipo, o vínoles alguna súbita salud que en tanta desesperación les diese la vida? Porque te hago saber que mientras tú has hablado, yo he estado lleno de pena por el temor que dellos tenía". 


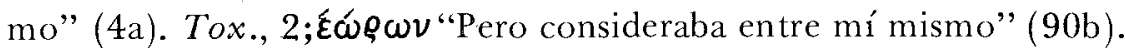

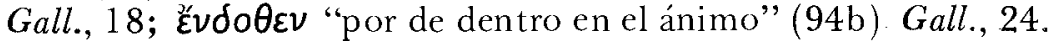

Hay alteraciones y mayor énfasis en los personajes de acuerdo con la preocupación didáctica y la sensibilidad social de la ápoca. En el relato de Mnesipo (Toxaris) sobre la amistad de Agátocles y Denias, y del encaprichamiento de éste con Cariclea, el traductor describe a los amantes con el léxico característico por los versos amatorios pastorales y de la novela sentimental de la época. En donde el satirista griego nota la facilidad promiscua de Cariclea para "aceptar al momento" a todo el que la mire, la Cariclea española "luego inclinaba sus ojos blandos y miraba amorosamente como deseosa de complacer a todos" (13b). De la misma manera, la descripción de Luciano cuando Cariclea manda a su sirvienta a sobornar a Denias, es mucho más sucinta que la del traductor quien, solazándose en los afectos, hace que la sirvienta visite a Denias "para que le declarase la fatiga que por él pasaba, cómo sin cesar derramaban lágrimas sus ojos, cómo en toda la noche no podía dormir de amor y de cuidados, a la fin dándole a entender que si no era dél remediada que ella se mataría a sí misma antes que padecer tan triste vida" (15a). Finalmente, mientras que la Cariclea de Luciano sabe cómo "suspirar miserablemente", la dama del traductor supera a su predecesora con mucho "sospirando miserablemente... con tan profundos sospiros que parecía romperse el pecho" $(15 b)^{54}$.

E.l traductor también señala el contraste entre la inocencia de Denias y la astucia de Cariclea: el "Denias" de Luciano es "el pobre mancebo de Denias" (15a). Este énfasis exagerado sirve para disculpar a Denias de manera no explícita en el original griego, y para poner también de manifiesto el interés del traductor en justificarlo. Sin embargo, la mayor justificación de Denias es la condición apenas mencionada por Luciano, pero enfatizada por el traductor en toda oportunidad posible, esto es, la locura, la enfermedad de todas

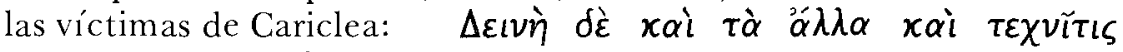

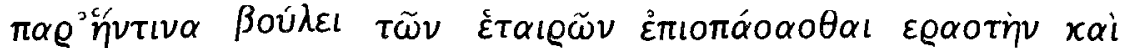

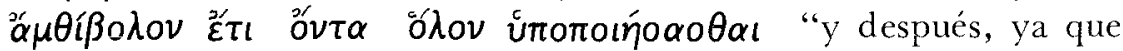
había hecho suyos, sabía por excelencia usar infinitas artes para encenderlos más en su amor, hasta sacarlos fuera de sentido, unas veces airándose contra ellos, otras veces haciendo paz y halagándolo con suaves palabras..." (14).

Mientras Luciano sólo hace notar que Denias no podía soportar estar sin Cariclea, el traductor escribe que "no podía sufrir su absencia, ni estaba en sí cuando no la veía" (16a). Cuando ella finge estar embarazada, buena manera, según Luciano, de encender a "un amante lento", el traductor lo sustituye por "loco enamorado" (16a).

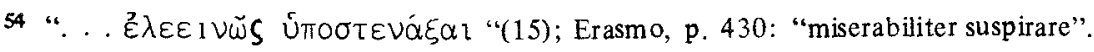


Cuando Luciano describe la locura de Denias, el traductor habla del joven "ajeno de sentido y de todo punto furioso" (16b).

A lo largo de los Diálogos, locura y sus sinónimos cubren una gran área semántica, supliendo en la traducción a muchos términos que en el texto griego son sólo parcialmente sinónimos: $\lambda u ́ \tau \tau \alpha$ (Tox., 15), 'rabia', 'furia' es traducido "ajeno de sentido y de todo punto

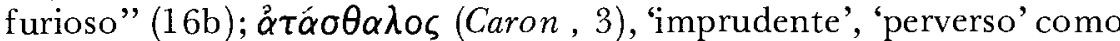

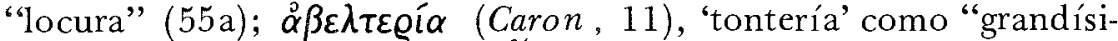
ma vanidad y locura" (62a); $\alpha$ y voเ $\alpha$ (Caron, 15), 'ignorancia' por

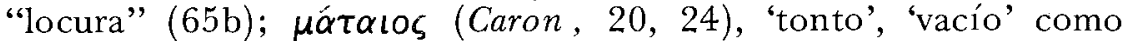
"locos" (68). También engaño cubre una gran área semántica:

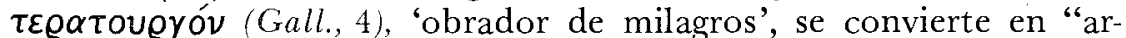
tífice de muchos engaños" (78b); $\pi \alpha \varrho \alpha \beta \lambda \varepsilon ́ \pi \omega($ Necrom., 1), 'ver mal', 'mirar con desconfianza', se convierte en "si de todo punto yo no me engaño" (103a).

La moral de los personajes se presenta con tintes más señalados que en el original: los amigos de Denias son más corruptos, los buenos amigos más verdaderos, el conocimiento de Menipo sobre las respuestas cósmicas es más profundo en el Icaromenipo español.

Aunque la mayoría de los reajustes se originan por el deseo del traductor de intensificar las emociones y de infundir sensibilidad contemporánea al modelo griego, también son importantes las revisiones realizadas para presentar un Luciano más moral y metafísico, es decir para traducirlo "cristianamente" 55 , algo que se advierte sin difi-

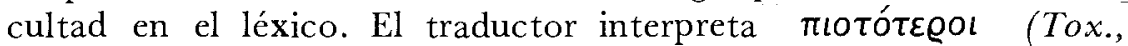
9), 'mucho más fiel', como "con mayor religión y diligencia" (10a);

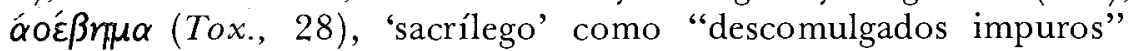
(26a); of "̈yıı (Gall., 23), 'miserables', 'lastimeros', como "los

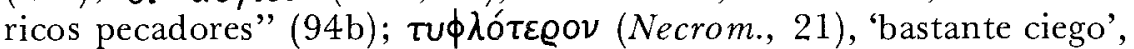
como "perdido y errado" (109a). De hecho, alguna traducción alcanza tonos ascéticos: $\tau \tilde{\omega} \beta$ ßíw (Caron, 19), por ejemplo, se transforma en "en el desierto de esta vida" (76b).

El traductor enfatiza la responsabilidad del hombre por sus acciones al final de la vida: "A estos tales [ricos] aborrece sobremanera Minos abominando su soberbia y fausto de la cual se ríe como aquel que sabe que en muy breve tiempo vendrán al pagadero donde serán castigados" (110b).

En Caron, 17, el traductor intercala un largo comentario de resonancia claramente medieval (por ejemplo, el uso de la personificación y el debate) sobre aquellos que se resisten a la muerte: “. . pónense

$55 \mathrm{El}$ traductor ya sea por error o a propósito malinterpreta lo que es aceptable al público cristiano. En Gállo, cuando Micilo de Luciano ruega al gallo que le revele su futuro, pretende ahorcarse si su próxima vida le of rece algo más que su actual pobreza. E1 Micilo español también promete ahorcarse, pero de desesperación. Aunque el suicidio sería reprobable en ambos casos, el del Micilo español ya no tiene la racionalidad filosófica de la transmigración de las almas como base. 
en armas contra ellos los ministros de la muerte sin querer obedecerlos, cuando de parte de aquella reina de todos, Muerte, le llaman. Pues, ¿qué piensas ser la causa de tanto atrevimiento y desobediencia? Por cierto que no era otra sino el vano pensamiento que tiene de vivir aquí para siempre, sin pensar jamás que han de ser de los bienes presentes apartados" (68a).

En el diálogo sobre la amistad, aunque el Toxaris de Luciano hace notar que la amistad es "admirable y digna del honor divino" autor en ningún momento destaca el origen divino de la amistad que

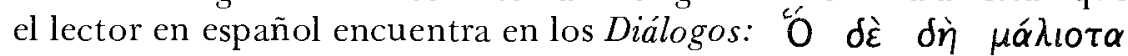

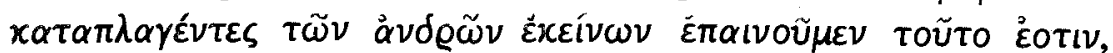

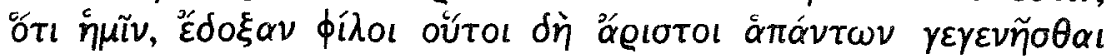

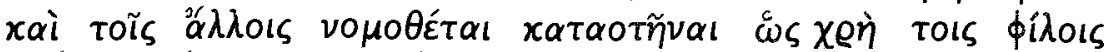

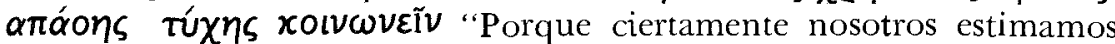
haber sido amigos el uno para con el otro, fidelísimos y constantísimos y que con sus obras de verdaderos amigos dieron ejemplo a los hombres, y casi pusieron una ley de inviolabe amicitia para que sepan los que quieren legítimamente usar de este divino don de amicitia, que es una centella de divinidad, que los dioses en la tierra sembraron..."

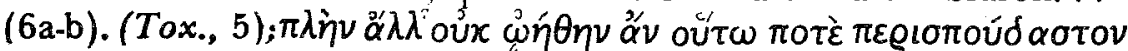

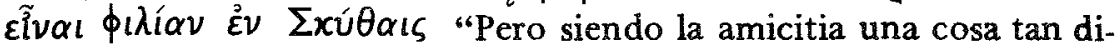
vima, no pensé que pudiera hallarse entre los scitas" (9b). Tox., 8.

En Icaromenipo, el traductor altera algunos pasajes para adecuarlos a su sensibilidad religiosa: el demiurgo de Luciano se convierte en "el autor" de la "admirable y artificiosa máquina" del universo ${ }^{57}$. Menipo expresa su aprobación de ciertas teorías cósmicas ${ }^{58}$; la contienda entre las escuelas filosóficas paganas se exagera ${ }^{59}$.

Tal vez el pasaje más interesante de todos los Diálogos para un lector español de mediados del siglo XVI es la declaración de un personaje en Toxaris, 53 a su amigo de que son miembros de un cuerpo común. Aunque la unidad biológica del estado tiene fuentes claramente clásicas, y el traductor ha interpretado el original con bastante exactitud, hubiera sido raro que el lector de 1550 no notara las resonancias paulinas (1 Cor: 6, 12; Ef: 4) en el siguiente pasaje:

En verdad pues que también sería cosa de burla, siendo como nosotros somos mucho tiempo ha con ley de amicitia juntados y hechos mismo cuerpo si tenemos por cosa muy grande que un miembro o parte nuestra ayude y sirva con toda diligencia a todo el cuerpo. Pues que en la verdad por sí mismo lo hace siendo como es una parte de todo aquel cuerpo que ha recebido el beneficio (42a), Tox., 53.

56 Toxaris, 3.

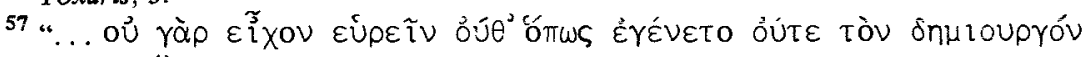
(Icaromenipo, 4).

58 Icaromenipo, 7.

59 A la observación de Luciano de que las discusiones filosóficas son infantiles ( in $\mu \alpha ́ x \eta$ ), el traductor agrega: "porque sobre estas cosas pelean unos contra otros, y aun algunas veces se levantan entre ellos batallas sangrientas" (125b). 


\section{LÉXICO Y MÉTODO DE TRADUCCIÓN}

El lenguaje de la traducción es, en general, el normal en la época; a veces hay giros populares que recuerdan al Lazarillo: ž́

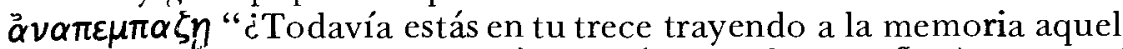

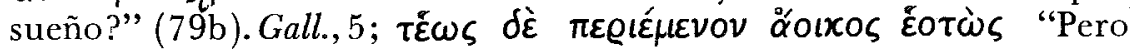
entre tanto andaba siempre a sombra de tejado vagabundo sin entrar

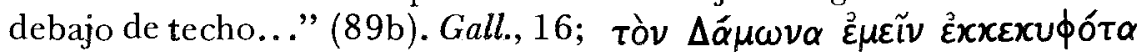

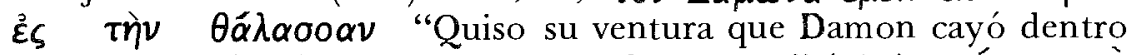

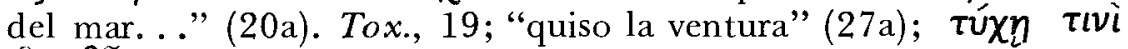
$\ddot{\alpha} \gamma \alpha \theta \tilde{\eta}$."quiso mi buena fortuna" (82a). Tox., 28.

El traductor cae en varios anacronismos. El ỏßohós de Luciano se convierte en "blanca" o "maravedí" (54b). Mientras que el Micilo de Luciano observa la sombra del reloj solar para no llegar tarde a casa de Eucrates, en el texto español está "mirando siempre a la mano del relox" (82b). El mismo deseo de una traducción vívida del original que motivó todas las alteraciones mencionadas, muestra que el traductor evita términos antiguos, aunque correctos, y usa anacronismos (el mismo Luciano utiliza dicción post-"ática" cuando la palabra aceptada resulta demasiado rígida o académica) ${ }^{60}$.

Aunque Menéndez Pelayo destaca los galicismos del traductor, sorprendentemente, no menciona el número bastante considerable de latinismos y helenismos que son mucho más ilustrativos para determinar el método de traducción.

Latinismos como "virtud" (5a) ${ }^{61}$, "excelencia', "estudio" (32a), 'celo', "glorioso" (77a), 'jactanciosos', "claros" (86b), 'famosos', "generosos" (5b) ${ }^{62}$, 'bien-nacidos', así como "celeridad" (107a), "Septentrión" (57a), "amicitia" (6a, 6b), "compelieron" (29b) y "facultades" (85a), sugieren que se utilizó el texto latino para la traducción ya que no sería factible que una traducción directa del griego al español hubiese dado consistentemente los mismos latinismos que la edición latina facilitaba al traductor. De hecho, hay momentos en que el traductor parece darse cuenta del latinismo como tal, como por ejemplo cuando añade a "celeridad", "presteza" que es más fácil de entender (107a).

Estos latinismos son especialmente significativos porque a menudo corresponden a los términos usados por Erasmo y señalan una probable fuente intermedia u obra de referencia para el traductor. También como Erasmo, el traductor cambia los dioses griegos por sus

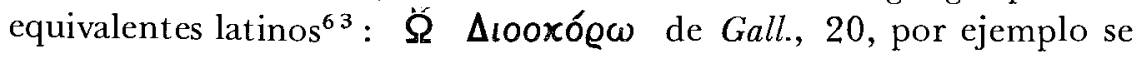

60 Para la sátira de Luciano sobre los puristas del estilo, véase Lexipha nes; Erasmo aplica la crítica de Luciano a los puristas del latín de su época en Ciceronianus.

61 Erasmo, p. 427: "virtus"; A. M. Harmon traduce "manhood" (hombría).

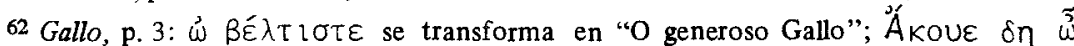
$\theta \alpha u \mu \alpha ́ \sigma l \varepsilon$ (Toxaris, p. 5) se traduce como "Oye pues un poco tú, varón muy generoso" (5b) y en Erasmo, p. 426: "O vir admirande".

63 Donde Luciano pone "Artemis", Erasmo y el traductor ponen "Diana"; donde "Ares", el traductor pone "Marte". 
convierte en "O Castor, o Pollux" (92a). Finalmente, ambos traductores modelan los sustantivos del original del latín y no del equivalente griego: por "Ajax", el traductor da "Aiace"; Erasmo nos da "Aiacem", donde el acusativo griego del original era "Á $\iota \alpha \nu \tau \alpha{ }^{64}$; de la misma manera, la frase del traductor, "el lago Pyriphlegetonte", sugiere derivación del acusativo latín "Pyriphlegethontem", más

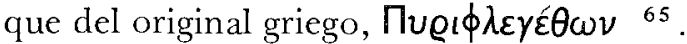

La aparición de ciertos errores en la traducción, fortalecen la sospecha de que hubo una fuente latina intermedia: $\quad \pi \lambda \dot{\eta} \nu$ oủx $\vec{\varepsilon} \mu \grave{\varepsilon}$

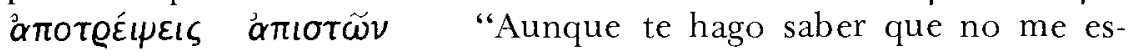

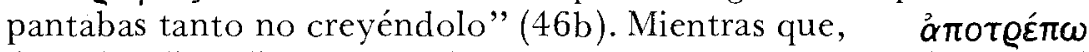

'irse de, disuadir', no podía por lógica dar "espantabas", pero sí el término latino, deterreo, 'disuadir', pero también 'ahuyentar' (usado por Erasmo p. 445).

Aparte del léxico también la gramática sugiere, ocasionalmente, el uso de una ancilla latina. Por ejemplo el uso subjuntivo en las pregun. tas indirectas es característico del latín (pero no del griego). Compá-

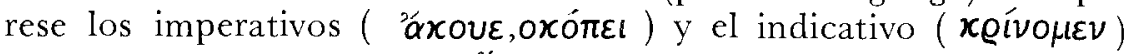

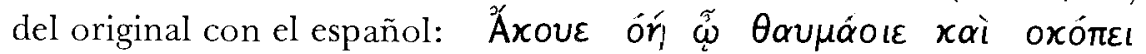

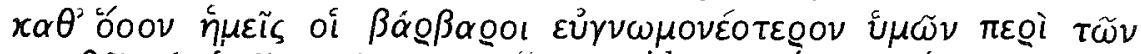
$\alpha \gamma \alpha \theta \tilde{\omega} \nu \hat{\alpha} \nu \delta \varrho \tilde{\omega} \nu$ $\varrho i ́ v o \mu \varepsilon v$, "y considera cuánto más rectamente nosotros, que somos tenidos por bárbaros, sintamos y cuánto más claro juicio que vosotros juzguemos de los señalados varones" (5b).

De la misma manera el uso del participio presente etimológico

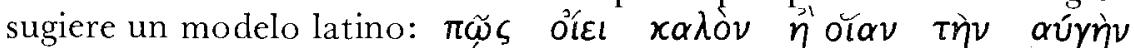

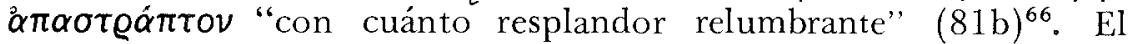
lapsus "mirad con cuánta facilidad y quam poéticamente" (56b) parecería una copia literal aunque no intencional con el texto latino a la vista.

Aunque haya pruebas abundantes de un texto latino que no se menciona, los múltiples helenismos de los Diálogos, algunos de ellos extremosos y desconcertantes, aseguran la pretensión de que Luciano fue traducido del griego, o por lo menos con la copia griega a la vista.

En primer lugar, la traducción incorrecta de una serie de sustantivos comunes por sustantivos propios, parecería indicar que en deter-

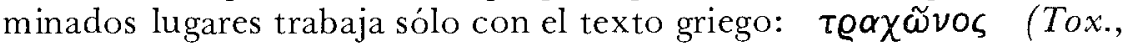
49), 'plano', 'trozo de tierra pedregoso', se convierte en "Thracon" $(40)^{67}$ como si de hecho el sustantivo fuese un toponímico o un fal-

64 Diálogos, p. 89 b; Erasmo, p. 480.

65 Diálogos, p. $110 \mathrm{~b}$; Menippus sive Necyomanteig, 10; de la misma manera la traduc-

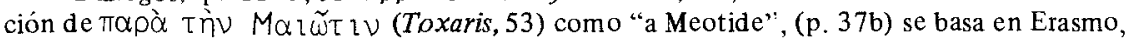
"in Maeotidem".

66 Erasmo, p. 475: “Quo fulgore coruscantis. . "

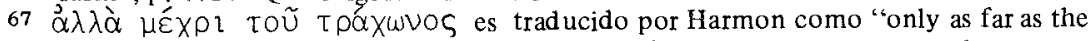
stony ground". Erasmo. como el traductor, toma $\tau \rho \alpha \chi u ́ s v$ como toponímico, ¿tal vez como falso afín de Thrax, 'tracianos"? 
so afín de thrax, "tracio". De la misma manera, la traducción de

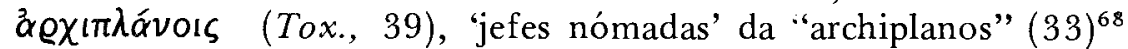
sugiere una fuente directamente griega, lo mismo que "’ं xivaıðov ẳ $\varepsilon x \tau$ @úvo (Gall., 27), "un gallo lascivo", como "ni gallo que sea

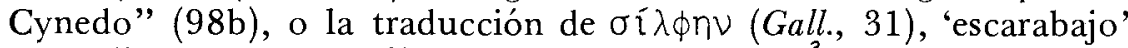
como "Sylpha" (110b) ${ }^{69}$. La transliteración de "Ẹivúas (Necrom., 9) por "Eriñes" (110b) cae también dentro de esta categoría.

Luego, varios errores en la traducción sólo pueden explicarse como calcos de palabras griegas: Moıvà (Necrom., 9), "diosa de la ven-

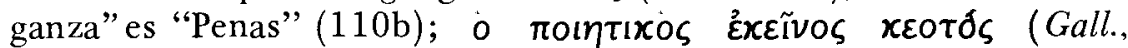
14), 'ese cinturón poético de Afrodita', se convierte en "cesto poéti-

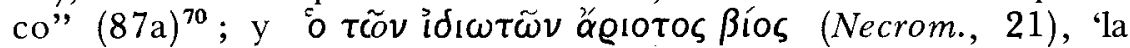
mejor vida es la de la gente común', se convierte en "la mejor y la más prudente vida de todos es la de los hombres idiotas" (109b).

Por último, la aclaración insuficiente de ciertas palabras sugiere que el autor está trabajando con un texto griego: la explicación de la

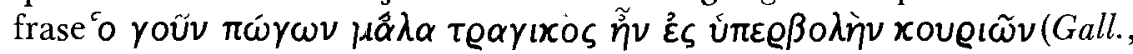
10) como "la barba tenía por extremo trágica, quiero decir, de cabrón" $(83 b)^{71}$ podría aún con su glosa engañar a cualquier lector que no estuviera familiarizado con los significados de "cabruno', 'trágico,"72.

La afirmación, en la primera página de los Diálogos, de que se trata de una traducción del griego, no es suficiente para eliminar las dudas que provocan los helenismos y latinismos constantes, tanto como las confusiones que sugieren una copia a la letra. Al parecer el traductor aplicó el método normal en la época de leer griego con la ayuda de una traducción latina ${ }^{73}$.

\section{DisCURSO DIRECTO E INDIRECTO DE LA NARRACIÓN}

Al traducir los diálogos al español, el traductor no respeta sistemáticamente la diferencia entre oratio recta y oratio obliqua. Como en griego el tiempo del verbo en la cita indirecta es el mismo que se usó en la elocución original, el diálogo griego aun narrado está más cercano a las palabras textuales que lo estaría en una traducción aunque fuese literal, en español; los relatos que se cuentan en la casa del Eucrates (Philopseudes), por ejemplo, se aligeran constantemente con los informes del narrador, de interrupciones, discursos, exclamacio-

68 Hasta Erasmo se siente obligado a.explicar el término, p. 439: "haud scio quo consilio Archiplanorum, id est, ducum nostrorum".

69 Gallo, $31 ;$ Diálogos, p. 110 b; Erasmo, p. 487.

70 Erasmo, p. 479: "cestus ille poeticus".

7 Erasmo, p. 416: "At barba mire erat tragica, id est, hircina".

72 En otro pasaje traduce $\tau \rho a \gamma$ $\ldots \tilde{\omega} \zeta$, "con estilo trágico' como "trágico y peregrino", sin glosa: cf. Necyomanteia, 8 y Diálogos (110a).

73 Francisco Vergara recomienda explícitamente un texto latino (De graecae linguae grammatica, p. 9). 
nes y observaciones de los oyentes, suspensión de narración pura hecha especialmente gráfica por la estructura de tiempos griega.

En los Diálogos, hasta la cita directa se convierte en indirecta, aunque ocasionalmente ocurre al revés. En el original, estas alteraciones destruyen la proporción del diálogo y la narración de la obra, que debe haber sido una de las grandes preocupaciones de Luciano puesto que las piezas estaban destinadas a ser leídas por un solo lector; las alteraciones del traductor, de hecho, hacen de los Diálogos más bien narraciones en prosa.

En el siglo XVI, la falta de sensibilidad o la despreocupación respecto al tipo de discurso puede reflejar el papel restringido que daba la retórica clásica a la expresión directa en la narración en prosa ${ }^{74}$ : prácticamente hay un silencio total en los tratados clásicos sobre la oratio obliqua ${ }^{75}$ y a la variedad de voces narrativas en general, extraña laguna en vista de su importancia obvia en el estilo de la prosa latina y griega. Los dos géneros de la antigüedad que podrían haber dado material para la creación narrativa, la novela bizantina y la sátira menipea, casi no se tratan en la teoría clásica.

El traductor de los Diálogos produce en lo estilístico un texto aproximado al original, pero, al parecer, no advierte ni la flexibilidad de Luciano en la voz narrativa ni su distinción que hace en el discurso. Tal vez esto señale la enorme distancia en la percepción artística que hay entre el autor del Lazarillo y Cervantes, y sus contemporáneos: los primeros tuvieron en cuenta el valor estético del estilo directo y el efecto de cambios abruptos en las voces de la narración $^{76}$.

74 En la teoría clásica, el diálogo y el discurso dicho son propios del teatro. La oratio recta en prosa narrativa (sermonicatio) se restringía a ciertas fórmulas, algunas de las cuales eran exclamativas, no dialogadas (Quintiliano, Institutio oratoria, ix, 2, 37.40).

75 La afirmación de Quintiliano de que Livio utiliza la oratio obliqua (ix, 2, 37) es la única referencia en la obra de los preceptistas latinos sobre este tipo de discurso.

76 En el Lazarillo hay un cambio en la voz narrativa en la descripción de la reacción del narrador al golpe recibido del amo: "Sintió el desesperado ciego que agora tenía tiempo de tomar de mí venganza, y con toda su fuerza, alzando con dos manos aquel dulce y amargo jarro, le dejó caer sobre mi boca, ayudándose (como digo) con todo su poder, de manera que el pobre Lázaro, que de nada desto se guardaba, antes, como otras veces, estaba descuidado y gozoso, verdaderamente me pareció que el cielo. . . me había caído encima" (Tratado primero). Para la relación entre Luciano y el Lazarillo, véase F. LÁzARo CARRETER, Lazarillo de Tormes en la picaresca, Barcelona, 1972, pp. 28-32. Para la discusión del cambio entre oratio recta y oratio obliqua en Cervantes, véase ANGEL ROSENBLA T, La lengua del "Qui. jote", Madrid, 1971, pp. 332-337. Aunque los críticos generalmente han enfrentado la teoría de la novela desde el punto de vista aristotélico (A. K. Forcione, Cervantes, Aristotle and the Persiles, Princeton, 1970; RUTH S. EL SAFFAR, Novel to romance, Baltimore, Maryland, 1974; E. C. RILEX, Cervantes's theory of the novel, Oxford, 1962), un problema importante, y que la crítica ha tocado apenas, es la falta de categorías retóricas específicas que permitan una amplitud y flexibilidad suficiente a la voz narrativa; tampoco se ha estudiado la dimensión relativa del estilo directo, vivencial, e indirecto (que Pfandl sí destaca en su Historia de la literatura nacional española). Es sorprendente notar que entre Cárcel de amor de Diego de San Pedro (1492), constreñida en sus fórmulas retóricas, y el Quifote (1605-1615), con su inmensa elasticidad en la narración, prácticamente no hay evolución en las categorías retóricas de la composición en prosa, a pesar de la aceptación crítica general de la Aethiopica en el siglo Xvi. 
El traductor no anota las citas que Luciano hace de Homero a menos que se especifiquen como tales, de modo que mucho del sentido de la frase se pierde. No advierte que la cita es directa, y más aún la traduce mal. En otros casos las citas homéricas se absorben en la des-

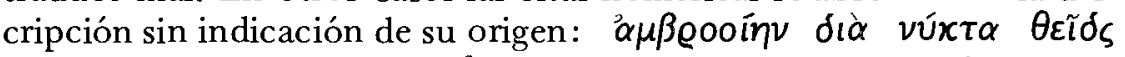

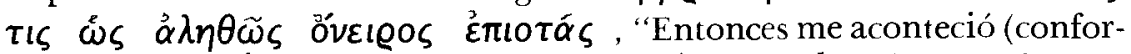
me a las sentencias de Homero) que me parecía estar cabe mí sueño divino y más dulce que la misma Ambrosia, mantenimiento muy suave de los dioses" (81a). Gall., 8.

Cuando el traductor advierte que hay versos, los traduce del griego en metros y estrofas contemporáneas, pero sin consistencia. En $\mathrm{Ca}$ -

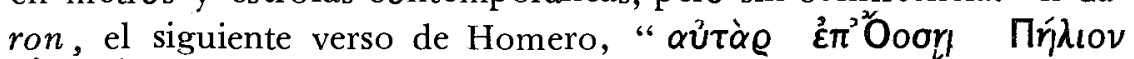
Eivoo í $\phi \lambda \lambda$ ov" se traduce en arte mayor "Pusieron sobre Ossa a Pelion frondoso"7 7. En Menuppus sive Necyomanteia, el traductor pone el trímetro yámbico en verso de arte mayor o como quintillas octosílabas (103a), y a pesar del cambio de metro, con poca consistencia, conserva la exhortación de Luciano a Menipo, "dexa los cruentos iambos"78, tampoco explica su agregado de "cruentos", que sólo haría sentido a quien estuviese familiarizado con el metro trágico griego.

\section{EL TRADUCTOR SOBRE LA TRADUCCIÓN}

En muchos puntos de los Diálogos el énfasis o las adiciones del traductor revelan sus propias ideas sobre la relación de la ficción con la verdad y el papel de la retórica en esa relación. Antes que nada, el traductor resalta, más que Luciano, los efectos de la retórica en el

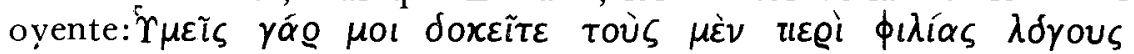

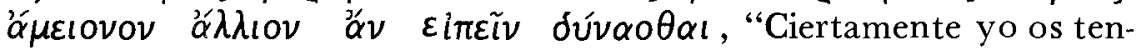
go a vosotros por tales que me parece que podréis con mayor elegancia y con mayor pompa de palabras disputar de la amicitia" (10b). Tox., 9;

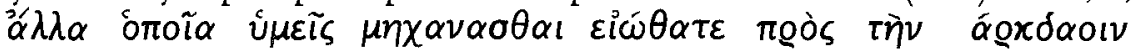
"y otras cosas a estas semejantes, cuales vosotros sabéis añadir con singular artificio para halagar y ablandar los oídos y mover los ánimos de

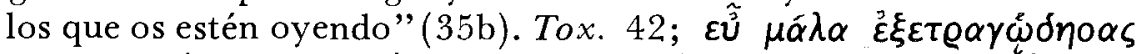
"como retóricamente tú representabas" (11b). Tox., 11. Este énfasis corresponde a las extensas amplificaciones afectivas y a las intensificaciones del original.

El traductor señala también el contraste entre la ficción y la verdad, tema de la poética aristo télica en boga a mediados del siglo XVI en la crítica literaria: $\mu \eta \delta \dot{\varepsilon} \nu \pi \alpha \varrho^{2} \varepsilon \mu \alpha \cup \tau 0 \widetilde{v} \quad \varepsilon \pi \pi \tau \varrho \alpha \gamma \omega \delta \tilde{\omega} \nu$ "sin fingir yo del mío alguna cosa, ni ensalzar ni disminuir nada que de verdad

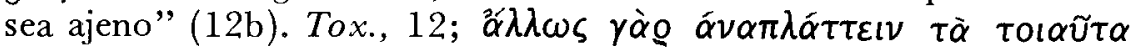

77 Toda la traducción del Idilio de Moscos que sigue a los Diálogos está también en arte mayor.

78 También el verso en Gallo, p. 7, está en quintilla. 
"porque inventan algunas nuevas patrañas" (12b). Tox., 11; $\pi \alpha ́ v v$

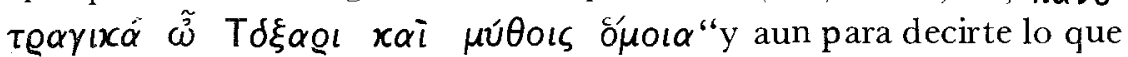
siento, a fábulas más que a verdad semejantes" (45a) $)^{79}$ y Tox., 56.

En algunos momentos el traductor menciona lo creíble y lo in-

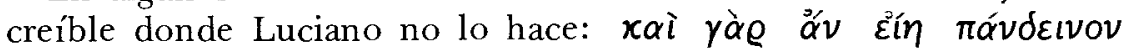
"Porque ciertamente sería cosa muy fea y casi increíble". (11b).

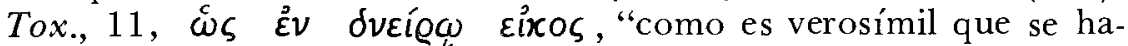
ce todo prestamente entre sueños" (85a). Gall., 12.

Como la mayoría de los autores de su época, el traductor considera importante el efecto de la admiratio. En algunos casos, eleva la nota de asombro presente en el original, pero igualmente a menudo (como en el caso de la traducción libre de locura), traduce erróneamente

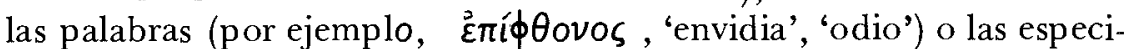
fica $\mu \varepsilon ́ \gamma ı \tau \tau o \nu$, 'grandioso', 'muy impresionante') para enfatizar el sentido de maravilloso: $\pi \alpha \nu \tau \varepsilon \lambda \tilde{\omega} \varsigma \pi \alpha \varrho \alpha ́ \delta o \xi \alpha$ "de todo punto admira-

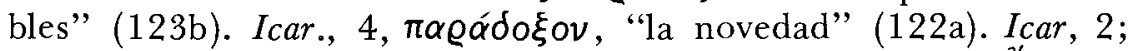

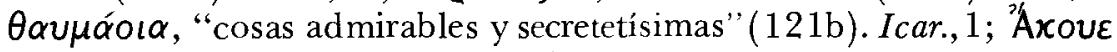

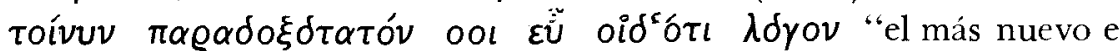

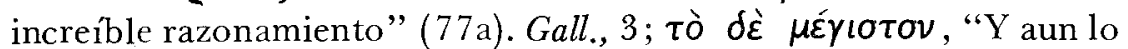
que es más de maravillar" (87a). Gall., 14.

El traductor tiende también a agregar topoi clásicos que no están

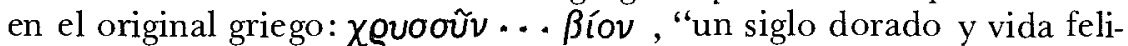

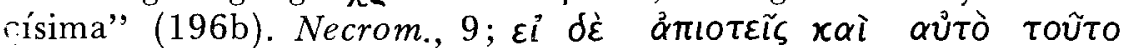

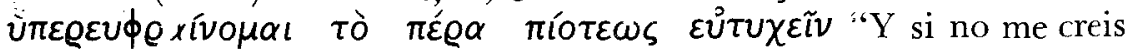
[sic] , hago te saber que por esto yo me huelgo estremadamente considerando ser mi felicidad tan grande que a esta causa no puede ser creída de los otros hombres plebeyos y vulgares, que ignoran la dignidad de su grandeza" (121b). Icar., 2. En ningún momento en el original griego se sugiere "un siglo de oro" o la distinción horaciana entre el hombre de gusto y la multitud.

En conjunto, las pequeñas aunque numerosas divergencias de ver$b a$ y res del texto original presentan al lector de 1550 un Luciano "naturalizado": dejando su pasaporte griego (y latino) junto con mucho de su bagaje retórico y cultural en alguna frontera no definida en la mente del traductor, sale de la imprenta de Gryphius en 1550 hablando un lenguaje retóricamente "clásico" - bien lejos de su nativa brevedad ática - y demostrando una sensibilidad contemporánea aceptable.

El traductor, más que igualar el estilo de Luciano, usa los estándares contemporáneos de copia y eloquentia para llegar a un estilo que él considera más apropiado para la traducción de un texto clásico, procedimiento, como otros muchos en los Diálogos, comunes en la época ${ }^{80}$. Donde amplía el original, la fórmula oratoria refuerza la re-

79 Erasmo, p. 445 : "tragica prorsus, o Toxari, fabulisque similia".

80 F. R. Amos, Early theories of translation, p. 100. 
sonancia clásica del español como lo hacen los loci interpolados. Un español clasicista o académico representaba el compromiso del traductor entre la lengua de Luciano y la propia.

Pero los cambios en la caracterización de los personajes parecen más aún de su época. Más profundos en las emociones y sus dimensiones interiores más explícitas, los personajes de los Diálogos recuerdan a los de Cárcel de amor o La Celestina. Sus reacciones sociales y éticas corresponden a lo que el contexto cultural del traductor dictaba. Más aún, el traductor recurre a un vocabulario lo suficientemente "cristiano" para permitir al lector destellos del anima naturaliter Christiana.

A juzgar por los numerosos escritores españoles del Siglo de Oro - no familiarizados con el griego- que citan a Luciano, el satirista debe haber sido leído ampliamente en traducción como autor clásico de "honesto entretenimiento". Los Diálogos, en su versión "naturalizada", eran, en el ámbito de la influencia en la literatura del Siglo de Oro, punto intermedio entre el texto griego, accesible a un puñado de helenistas, y la literatura vernácula que, inspirada con intensidad diversa en las obras de Luciano, comparte, en un sentido amplio, el arte de la traducción ${ }^{81}$.

MiChAEL ZAPPALA

St. Lawrence University, New York.

81 Sobre la imitación como tipo de la traducción, véase REUBEN BRower, Mirror on mirror, Cambridge, 1974, p. 2. 